\title{
Ritos y milpas en Amatlán de Quetzalcóatl, Tepoztlán, Morelos, México
}

\author{
Rites and Cornfields in Amatlán de Quetzalcóatl, Tepoztlán, Morelos, Mexico
}

Erika Román Montes de Oca

UNIVERSIDAD AUTÓNOMA DEL ESTADO DE MORELOS, kikarome17@hotmail.com

En este trabajo conoceremos la importancia que tienen los ritos, mitos y tradiciones en la continuidad de la producción milpera de Amatlán de Quetzalcóatl. El estudio se llevó a cabo a través de la investigación cualitativa mediante el método etnográfico; asimismo, se hizo de forma cuantitativa, se realizaron 95 encuestas a las familias de la comunidad. En la información obtenida se encontró que los campesinos siguen cultivándola, no por negocio, sino por cultura, identidad, autonomía y, sobre todo, porque es su seguridad alimentaria. Los rituales, mitos y fiestas de la milpa generan vínculos de amistad y disminuyen tensiones de la vida diaria por la convivencia que se genera en estos eventos. Sin embargo, con el paso de los años cada día las familias los realizan con menor frecuencia debido a que su actividad económica ya no sólo es la agricultura, sino ahora dependen de otras fuentes de ingreso.

Palabras clave: identidad, milpa, rituales, mitos, tradiciones.

This article discusses the importance of rites, myths and traditions in relation to the continuity of corn production in Amatlán de Quetzalcóatl. The research methodology adopted was qualitative using the ethnographic method, complemented by a quantitative approach that consisted in applying 95 questionnaires to families in the community. The information gathered revealed that these farmers continue cultivating the land, not as a business but, rather, for reasons associated with their cultural identity, autonomy and, above all, alimentary security. The rites, myths, and festivities related to their cornfields generate friendships and help relax the tensions that can arise among community members during daily life. However, as the years pass, families participate in these traditions less and less often because their economic activity no longer centers only on agriculture, but also depends on sources of monetary income.

KEYWORDs: identity, cornfields, rites, myths, traditions.

Fecha de recepción del artículo: 23 de marzo de 2015 / Fecha de aprobación: 8 de febrero de 2016 / Fecha de recepción de la versión final: 9 de marzo de 2016 


\section{INTRODUCCIÓN ${ }^{\mathrm{I}}$}

1 maíz ha sido, desde su domesticación hasta la actualidad, el
alimento principal para la población mexicana. Existe entre
la milpa ${ }^{2}$ y el humano una relación necesaria para la sobrevivencia de ambos que origina determinados ritos que contienen las creencias, conocimientos, tradiciones, mitos y prácticas religiosas de los productores de la milpa.

Además de que el maíz garantiza la sobrevivencia de los campesinos, es la actividad económica donde se involucra e interactúa la cultura, las relaciones sociales y la organización comunitaria. ${ }^{3}$ La cultura mantiene un vínculo central y estrecho con el desarrollo humano y con los procesos de formación por los que atraviesa el individuo para incorporarse en su entorno social, mantenerse y recrearse en él.

Algunos de los rituales y festividades, que se llevan a cabo alrededor del ciclo agrícola se continúan efectuando en comunidades cam-

${ }^{1}$ Este trabajo es resultado de la investigación de tesis doctoral "El maíz en la vida cotidiana de las familias campesinas de Amatlán de Quetzalcóatl”, realizada durante los años del 2010 al 2013, en el posgrado de Ciencias Agropecuarias y Desarrollo Rural de la Facultad de Ciencias Agropecuarias de la Universidad Autónoma del Estado de Morelos.

${ }^{2}$ El cultivo de la milpa en la comunidad de estudio consiste en la siembra de diferentes plantas, principalmente, maíz, frijol y calabaza. También se aprovechan especies silvestres que se desarrollan en la misma parcela y sirven de alimento. Milpa, vocablo de origen prehispánico. Terán y Rasmussen la definieron como un policultivo en cuyo corazón se encuentra la triada maíz (Zea mays), frijol (Phaseolus spp) y calabaza (Cucurbita $s p p$ ) junto con otras plantas que varían de una región a otra. Silvia Terán y Christian Rasmussen, "La milpa bajo roza-tumba-quema en el siglo Xvı", en La modernización de la milpa en Yucatán: utopía o realidad, ed. Daniel Zizumbo Villarreal, Christian Rasmussen, Luis Arias Reyes y Silvia Terán Contreras, 29-51 (Mérida: Centro de Investigación Científica de Yucatán, Danida-Dinamarca, 1992). Gutiérrez Serrano y Gómez Espinosa afirman que el concepto de "milpa" es el sistema prehispánico de producción agrícola y se encuentra vinculado no sólo con la producción, sino también con el mito y con la cosmovisión mesoamericana. Norma Georgina Gutiérrez Serrano y José Antonio Gómez Espinosa, "Relatos de vida productiva alrededor del maíz. Maíz, milpa, conocimiento y saberes locales en comunidades agrícolas", en Saberes colectivos y diálogos de saberes en México, coord. Arturo Argueta Villamar, Eduardo Corona-M. y Paul Hersh Martínez, 329-344 (México: unAm, 2011).

${ }^{3}$ Norma Georgina Gutiérez Serrano, "Cultura, conocimiento y aprendizaje”, en Relatos, conocimientos y aprendizaje en torno al cultivo del maiz en Tepoztlán, coord. Norma Georgina Gutiérrez Serrano, 55 (México: Juan Pablos, CRIM, 2010). 
pesinas donde el maíz tiene un lugar preponderante, son una forma de cohesión de la comunidad y una forma de identidad de grupo. ${ }^{4}$

Por lo tanto, el propósito de este trabajo es conocer si los ritos, las tradiciones y las ceremonias que se realizan alrededor de la producción de la milpa son factores importantes en la continuidad de la producción de este cultivo; además, saber si proporcionan identidad y autonomía.

En la comunidad, los campesinos se identifican con la siembra de la milpa, por ello es comprensible la continua vigencia y el sentido que tiene para sus miembros este cultivo.

Según Gilberto Giménez, ${ }^{5}$ identidad es el

Conjunto de repertorios culturales interiorizados (representaciones, valores, símbolos), a través de los cuales los actores sociales (individuales o colectivos) demarcan sus fronteras y se distinguen de los demás en una situación determinada, todo ello dentro de un espacio históricamente específico y socialmente estructurado.

La identidad es una construcción holística permanente, que no se limita al plano de lo cultural, sino que atraviesa todas las dimensiones de la vida cotidiana. La cultura según comenta Patricia Guerrero: ${ }^{6}$

Son atributos casuales, acontecimientos, modos de conducta, instituciones o procesos sociales; la cultura es un contexto dentro del cual todos esos procesos encuentran significado y significación, que tejen interacciones simbólicas que dan sentido a la vida de los seres humanos y las sociedades. La cultura, como construcción simbólica de la praxis social, es una realidad objetiva que le ha permitido a un grupo o individuo llegar a ser lo que

${ }^{4}$ Yolotl González Torres, "Notas sobre el maíz entre los indígenas mesoamericanos antiguos y modernos, Dimensión Antropológica, año 14, vol. 41 (septiembre/diciembre 2007): 75 .

${ }^{5}$ Gilberto Giménez, "Identidades étnicas: estado de la cuestión”, en Los restos de la etnicidad en los Estados nación del siglo XXI, coord. Leticia Reina, 54 (México: Ciesas, INI, Porrúa, 2000).

${ }^{6}$ Patricia Guerrero Arias, La cultura estrategias conceptuales para entender la identidad, la diversidad, la alteridady la diferencia (Quito: Abya-Yala, 2002), 76 y 103. 
es. Mientras que la identidad es un discurso que nos permite decir "yo soy o nosotros somos esto", pero que sólo puede construirse a partir de la cultura. De ahí que cultura e identidad sean conceptos diferentes.

En los sistemas de representaciones simbólicas se encuentran los rasgos diacríticos que forman parte de la memoria colectiva: los sistemas de creencias, los imaginarios, cosmovisiones, los valores, los mitos, los rituales que son elementos referenciales del pasado y del presente, que orientan la formación de la identidad. ${ }^{7}$

Coincidiendo con los autores, ya que para el caso de Amatlán, se puede decir que la identidad es un concepto polisémico, porque ha pasado por procesos ideológicos del pasado hasta el presente mediante normas, rituales, valores, cosmovisiones, signos, etcétera, basados en relaciones vivenciales que están ligados a su historia y a su herencia cultural. Se expresan en las actividades que realizan cotidianamente, en las celebraciones de sus ceremonias, ritos, fiestas, comidas, tradiciones; en el mismo espacio donde viven porque los habitantes se sienten diferentes a los pobladores de las comunidades circunvecinas.

Muestra de ello son los mitos, ritos y tradiciones relacionados con la producción de la milpa, que se llevan a cabo en la comunidad de estudio, ya que la cultura de este cultivo no se refiere solamente a las semillas y su forma de cultivarlas, sino a una larga lista de diversas dinámicas familiares y comunitarias de siembra, cosecha, intercambio de jornales, preparación de alimentos, celebración de fiestas, mitología, entre otros, ${ }^{8}$ que han mantenido la persistencia del cultivo. Debido a que la convivencia que se genera en el trabajo de campo, y cuando se realizan los ritos, provoca una conducta comunicativa que ocasiona un intercambio simbólico, material, intelectual, informativo y de reciprocidad. Dicho intercambio propicia mayor aptitud para la resolución de problemas en otros ámbitos de la vida cotidiana, ya que se trata de desarrollar una existencia dinámica en la que se

${ }^{7}$ Ibid., 104.

${ }^{8}$ Norma Georgina Gutierréz Serrano, "Relatos de vida productiva alrededor del maíz. Cultura, conocimiento y aprendizaje", Revista de Cultura, Identidad y Educación, año 4(7) (2009): 92. 
intercambian conocimientos, emociones y bienes materiales. ${ }^{9}$ Asimismo, estas actividades permiten su supervivencia frente a las transformaciones actuales y dinámicas del mundo actual. En este sentido se han realizado estudios donde los etnólogos han observado que la actividad ceremonial amortigua y mediatiza algunas de las presiones económicas, políticas e ideológicas de la sociedad dominante. ${ }^{10}$

Esta investigación contempla un análisis de tipo cuantitativo y cualitativo. El método cualitativo utilizado fue la etnografía, cuyos datos, tanto de la información verbal como de la no verbal, consisten en experiencias de los habitantes mediante la observación, para comprender lo que hacen, dicen y piensan sus actores; además, de cómo interpretan su mundo y lo que en él acontece. Fue necesario utilizar las técnicas de la observación participativa, la cual se realizó antes, durante y después de la investigación, se hicieron 10 entrevistas durante el periodo de 2011-2012, también se llevaron a cabo registros fotográficos y visitas de campo en los ańos de 2010 al 2013. Asimismo, se asistió a algunas fiestas y ceremonias; es decir, que en un periodo de tiempo se estuvo en contacto directo con la comunidad. En el análisis cuantitativo, en el año 2011, se aplicaron 95 encuestas a las familias de la comunidad, las cuales se hicieron casa por casa.

\section{LA COMUNIDAD}

Amatlán de Quetzalcóatl pertenece al municipio de Tepoztlán que se sitúa en el estado de Morelos. Las poblaciones circundantes son: al norte, Santo Domingo Ocotitlán y Tlalnepantla; al oeste, Tepoztlán e lxcatepec; al este, Tlayacapan; y al sur, Yautepec. La comunidad se localiza a quince minutos de la cabecera municipal de Tepoztlán, a treinta minutos de la ciudad de Cuernavaca y a una hora de la ciudad de México.

${ }^{9}$ Cristina Saldaña Fernández, Los días de los años: ciclo ritual en el suroeste de Morelos (México: Juan Pablos, 2011), 187.

${ }^{10}$ Catharine Good Eshelman, "La vida ceremonial en la construcción de la cultura: proceso de identidad entre los nahuas de Guerrero", en Historia y vida ceremonial en las comunidades mesoamericanas: los ritos agrícolas, Colección Etnografía de los pueblos indígenas de México. Serie Estudios Monográficos, coord. Johanna Broda y Catharine Good Eshelman, 127 (México: Conaculta, INAH, UNAM/IIH, 2004). 
La principal actividad productiva es la agricultura, $69 \%$ de las familias todavía se dedican a la siembra de la milpa. El cultivo es de temporal, y está destinado principalmente para el autoabasto y una pequeña cantidad (conocida como excedente) para venderlo dentro de la misma comunidad. De las 95 encuestas realizadas a las familias, se obtuvo que 66 continúan con la producción de la milpa para generar alimento y abastecer a la unidad doméstica y a los animales durante aproximadamente un año; en el periodo de secas las familias se incorporan a otras actividades. La mayoría de la población posee escasa tierra, un promedio de 1.10 ha por familia; sin embargo, la dedicación a la siembra de la milpa habla de la decisión de mantener, al menos, la posibilidad de alimentarse con cosechas propias. ${ }^{11}$ El promedio de cosecha es de $2 \mathrm{t}$. Así, cada familia logra obtener una cantidad suficiente para la alimentación de todos los integrantes de la familia y de los animales domésticos. En caso de que la producción no cubra el consumo necesario de maíz, el jefe de familia ${ }^{12}$ lo compra a sus familiares o vecinos que cultivan cantidades mayores. Las familias que ya no siembran la milpa, compran el maíz a los mismos campesinos de la comunidad o compran las tortillas hechas a mano en los puestos de la comunidad o en la tortillería.

Por lo anterior y en relación con los cuestionarios realizados en la comunidad se puede observar que la gente siembra el maíz que consume, en el año 2010 se tuvo una cosecha de 121.70 t y el consumo per cápita anual según SIAP-SAGARPA ${ }^{13}$ es de $123 \mathrm{~kg}$ en México. De las 345 personas consideradas en las unidades familiares encuestadas se calcula un consumo de 42.44 t de maíz aproximadamente, gra-

${ }^{11}$ En el año 2010 contaron con un área sembrada de aproximadamente 61.75 ha y una cosecha de $121.70 \mathrm{t}$, su orografía es mayormente montañosa, condiciones difíciles para la producción extensiva del cultivo, y en algunos lugares sólo se cultiva con yunta. La superficie de siembra en el 2010 fue: dos familias cultivan 3 ha, 15 entre 2 y 1 ha y 20 menos de una; con esto las cosechas para 45 de ellas son entre .075 y $1.5 \mathrm{t}$, y para 15 más de $1.5 \mathrm{t}$.

${ }^{12}$ Jefe de familia se considera al hombre mayor de la casa y quien aporta recursos para los gastos de las necesidades básicas, ejemplo: los padres, abuelos o hijos. En algunos casos se considera también a las mujeres responsables de mantener el gasto familiar.

${ }^{13}$ SIAP-SAGARPA, Situación actual y perspectivas del maíz en México 1996-2012, México, Servicio de Información Agroalimentaria y Pesquera, Secretaría de Agricultura Gana- 
cias a esto los habitantes aún pueden seguir consumiendo grano cultivado en su vida diaria. Los señores mayores de 41 años de edad son, principalmente, quienes siembran la milpa. Los hombres y mujeres de entre 15 y 40 años se dedican primordialmente al trabajo no agrícola; son los adultos quienes todavía están interesados en este cultivo, cada vez menos jóvenes prefieren continuar con el trabajo de campo, debido a que no hay buen precio en el mercado; sin embargo, no lo han abandonado por considerarlo necesario para el autoabasto y por tener un significado especial en su vida, en su identidad. El campesino pertenece a una sociedad que tiene una cultura propia, donde la familia es la unidad fundamental de análisis y que, en comparación con la economía de mercado, tiene un comportamiento económico que está al margen de la lógica del capitalismo. Ya que su lógica no consiste en ganar, sino que el comportamiento económico de los campesinos sólo se puede entender en términos de sus formas de vida y valores.

La comunidad es un pueblo indígena que se encuentra a $80 \mathrm{~km}$ de una de las ciudades más importantes del mundo, sometida a diversas presiones de aculturación, tanto a nivel nacional como local. Hoy son cada vez más visibles las transformaciones económicas y espaciales con una tendencia urbanizadora. No obstante, dichas transformaciones aún no alteran, de manera general, aspectos culturales, como: el trabajo colectivo, la organización familiar, la producción de la milpa, etcétera. Éstos siguen siendo elementos primordiales en las relaciones familiares y comunitarias. En coincidencia con Corona y Pérez, quienes mencionan que aun cuando la comunidad ha adaptado nuevos comportamientos a su perfil cultural, al asimilar los cambios tecnológicos y sobrevivir con sus relaciones de producción e intercambio capitalista, la lógica cultural del poblado se arraiga fuertemente en una organización comunitaria, que alude a una cosmovisión particular que exige relaciones de intercambio muy distintas de la lógica urbana. Este reclamo de reafirmar los modos propios de existencia se expresa al momento que los pueblos se

dería Desarrollo Rural Pesca y Alimentación, 2007, http://www.campomexico.gob.mx (Fecha de consulta: 31 de enero de 2015). 
ven amenazados en su cultura y sus valores por la imposición forzada de proyectos de modernización. ${ }^{14}$

Por ello, los campesinos que aún siembran siguen trabajando en la selección de su semilla y guardando ese recurso tan preciado para ellos, por dos razones principalmente: una, para tener que comer durante todo un ańo; otra por tradición, como parte de las creencias $\mathrm{y}$ actividades que han venido realizando a lo largo de su historia; por ejemplo, mediante los rituales.

Ya que los rituales permiten a cada sociedad expresar un respeto ante lo sagrado, establecer una continuidad en el tiempo, imprimir una lógica cultural al conjunto de momentos que marcan la vida social, a la propia existencia del grupo y, de esta manera, establecer un sentido histórico. ${ }^{15}$ Asimismo, la tradición se concibe como los patrones culturales que una o varias generaciones heredan de las anteriores y por estimarlos valiosos los trasmite a las siguientes. El cambio social altera el conjunto de elementos que forman parte de las tradiciones. Se considera tradición a los valores, creencias, costumbres y formas de expresión artística característicos de una comunidad, en especial, aquellos que se transmiten por vía oral.

Los conocimientos de los mitos, rituales y tradiciones se trasmiten a través de símbolos que se expresan por medio de normas, valores sociales y formas de conducta. ${ }^{16}$ Por eso, para los campesinos de Amatlán, el respeto al cultivo de la milpa ha sido tan significativo: muestra de ello es que las creencias y los ritos sobre la milpa constituyen la matriz, el eje de su religiosidad, de ahí que los comportamientos y prácticas religiosas impregnen la vida social del grupo como parte esencial de su universo simbólico. ${ }^{17}$ Lo cual explica la

${ }^{14}$ Yolanda Corona Caraveo y Carlos Pérez Zavala, "Resistencia e identidad como estrategias para la reproducción cultural”, Anuario de Investigación, vol. II (2002): 57.

${ }^{15}$ INAI, Fiestas y rituales en la conservación de la agrobiodiversidad en el Perú (Lima: Instituto Nacional de Investigación Agraria, 2007).

${ }^{16}$ Alessandro Lupo, "La cosmovisión de los nahuas de la Sierra de Puebla", en Cosmovisión, ritual e identidad de los pueblos indígenas de México, coord. Johanna Broda y Felix Báez-Jorge, 365 (México: Fondo de Cultura Económica, 2001).

${ }^{17}$ Dora Sierra Carrillo, El demonio anda suelto. El poder de la cruz de pericón (México: INAH, 2008), 119. 
"terquedad" del campesino de sembrar maíz criollo, ${ }^{18}$ aun cuando los paradigmas de la modernidad y del progreso indican que es más fácil comprarlo que producirlo. ${ }^{19}$

Por otro lado, el mito como producto social ha surgido de fuentes diversas e innumerables, cargado de funciones, persistente en el tiempo pero no inmune a éste; es decir, su estructura permanece aunque cambie su forma, y como todo producto social adquiere su verdadera dimensión cuando es referida a la sociedad en su conjunto. ${ }^{20}$ Los mitos tienen la naturaleza de símbolo que, por poseer cierto grado de convencionalidad, son productos sociales. Se acepta también que el mito es una manera de representar el inconsciente colectivo cuya función esencial es expresar y mantener la solidaridad del grupo. Es decir, el mito alude a un acontecimiento pasado donde sucedió algo, es un fragmento del comportamiento verbal tradicional, ya que una tradición oral contiene información normativa, rasgos estructurales de la cosmología, los cuales aparecen en el contenido y la organización de dicha tradición. ${ }^{21}$ Ejemplo de ello es el mito del nacimiento del maíz en la comunidad de estudio.

\section{LOS MITOS RELACIONADOS CON EL CULTIVO DEL MAÍZ}

Los mitos forman parte fundamental de una comunidad: son un motivo más que les da identidad y persistencia, porque son relatos que se conciben como un complejo de creencias, como una forma de captar y expresar un tipo específico de realidad, como un sistema lógico o como una forma de discurso. El mito en la producción de la milpa ha estado presente desde su creación, se dice que los hombres estamos hechos de maíz, no sólo es el constituyente del cuerpo y del espíritu del hombre de maíz que le confiere su naturaleza hu-

${ }^{18} 68 \%$ siembra semilla criolla, $26 \%$ hibrida y $6 \%$ de las dos, datos obtenidos de las encuestas.

${ }^{19}$ José Antonio Gómez Espinoza, Maiz, axis mundi, Maiz y sustentabilidad (México: Juan Pablo Escobar, 2011), 15.

${ }^{20}$ Alfredo López Austin, Cuerpo humano e ideología las concepciones de los antiguos nahuas I (México: UNAM, 1980).

${ }^{21}$ Cristina Saldaña Fernández, Ritual agrícola en el suroeste de Morelos: la fiesta de la Ascensión (México: Plaza y Valdés, 2010), 256-257. 
mana, es también la representación del Dios creador, del que mantiene el orden del cosmos. ${ }^{22}$

En Amatlán de Quetzalcóatl, muchos ritos y tradiciones giran alrededor de la milpa, ya sea en relación con las acciones ambientales o productivas. Desde la época prehispánica este cultivo ha sido parte fundamental en la alimentación, la salud, la visión del cosmos y en su vivir cotidiano, por lo tanto, se ha mantenido a pesar de las imposiciones espańolas y modernas.

Este cultivo es y fue muy importante en la vida del mexicano, tanto es así, que en la historia de los mayas está contemplado que los humanos estamos hechos de maíz. La vida cotidiana se envuelve en el ritual agrícola, de ello depende el quehacer del hogar o de otras actividades extraagrícolas.

Amatlán tiene su propia historia, donde se cree que en ese lugar nació Quetzalcóatl, y fue allí donde dio sus primeros pasos. Según la antropóloga Carmen Cook, en el año Ce-Acatl, Uno caña, 843 d.C., nació Topiltzin, en Amatlán, en el sitio que se nombra Michatlahco, lugar de peces, allí donde sembraron su nombre. ${ }^{23}$ Sin duda alguna, para los amatlecos es significativo saber que ese personaje forma parte importante de la historia de los pobladores, ya que además de haber nacido allí, se cree que gracias a él nació el maíz. Así como en la cultura maya, los huicholes, los pobladores de Huastecapan, y otras culturas que plantean que en su lugar de origen nació el maíz, los habitantes de la comunidad estudiada tienen su propio mito sobre la creación de este grano, por lo tanto, es necesario considerar que a pesar de estar en lugares diferentes y de tener lenguas distintas, el significado mitológico y la simbología son similares. La gente sabe que existe y que no tiene una explicación científica, y que cada vez se va cambiando la esencia del mismo; sin embargo, lo consideran como parte de su pertenencia, ya que este permite la persistencia de representaciones, ideas y ritos que hacen que el sistema de la milpa continúe cultivándose hasta nuestros días, así como la

${ }^{22}$ José Antonio Gómez Espinoza, Maiz, 51.

${ }^{23}$ Carmen Cook, "El yauhtli o pericón. Flor mágica de los antiguos mexicanos", en La historia de Amatlán de Quetzalcóatl, comp. Felipe Alvarado Peralta, 33-35 (Cuernavaca: Anzaldo Meneses, 1987). 
reproducción de los campesinos. De las entrevistas realizadas, 80 \% sabe que ahí nació el maíz, gracias a Quetzalcóatl, quien pudo entrar a la cueva y obtener las semillas, como se presenta en el documento escrito por Alvarado. ${ }^{24}$

Quizá los entrevistados no conocen la historia como se presenta en el documento, pero saben que en el Cerro de la Puerta ${ }^{25}$ existe el tesoro que permitió que la gente de la comunidad se alimentara y terminara la hambruna. Se dice que cada año nuevo de la época prehispánica, se abre el cerro a cierta hora de la noche y quien tenga suerte de encontrarlo abierto, tienen la oportunidad de sacar las semillas que se encuentran adentro (que son las que se siembran en la milpa: maíz, frijol, semilla de calabaza y chile, principalmente) para poder seguir cultivándolas. Además, se comenta que existe un tesoro y quien logre salir del cerro lo hará al siguiente año nuevo y podrá disfrutar de lo que haya encontrado.

Como comentan los entrevistados:

Una vez tuve un sueńo, apenas la semana pasada y le platiqué a Lety [su hija], que estaba afuera del Cerro de la Puerta y que se abría, entonces miré y se veía mucho brillo, yo digo que era como oro porque estaba muy resplandeciente, que entraba y que veía muchas jarras y trastes de oro, pero que las dejé y mejor salí. ${ }^{26}$

De las personas encuestadas, $90 \%$ conoce la historia del Cerro de la Puerta, la cual es contada a los turistas que visitan la comunidad, y quieren conocer sus historias.

La puerta del cerro se abre nada más el último día del año nuevo, y se vuelve a cerrar casi enseguida, decían los abuelos que si alguien llegara a entrar, sentiría como si hubiera estado solo un ratito; pero al salir, si saliera, ha pasado un año o más, también decían que las personas que han logrado

${ }^{24}$ Felipe Alvarado Peralta, Fundación de Amatlán (Cuernavaca: Anzaldo Meneses, 1988).

${ }^{25}$ Nombre de un cerro que se encuentra ubicado en los terrenos de una familia de la comunidad, es un montículo muy alto que en la parte frontal tiene una línea bien trazada en forma de puerta.

${ }^{26}$ María Asunción Guerrero Robles (comunicación personal, 13 de febrero de 2012). 
entrar enseguidita se mueren. Una vez vinieron unos extranjeros y de repente perdieron a su amigo, lo buscaron y como no lo encontraron se fueron, después de dos o tres años dicen que el extranjero apareció y dijo que había estado en la puerta un rato y que había visto un inmenso tesoro, después se fue y ya nunca se supo de él. ${ }^{27}$

Otro mito que existe y que $75 \%$ de la encuestas realizadas dicen tener conocimiento de éste, es el Tlahcalli, se presenta al principio de cada temporada de lluvias, la gente de este pueblo siempre está al pendiente de la señal de la luz roja (es un color rojo que aparece en las nubes), esperan verla por la tarde o noche. Cada ańo varía la posición de la aparición de esta luz, dependiendo del lugar donde se encuentre se sabrá si anuncia buen o mal temporal. Por ejemplo: si aparece en el cerro llamado Xochiatlahco o Cuahutzin habrá buen temporal; pero si aparece en Meztliimanca, Cazaltepec o Tecoloatlahco es señal de mal tiempo.

Así lo manifiesta un campesino de la comunidad:

Empieza el temporal, ya empiezan las nubes, ahí está y ya es el tiempo, en las noches se está quemando y se ve que sube un resplandor rojo que se prende y se apaga y luego vuelve a prender y se apaga y nomás de momento vuelve a aparecer ese resplandor rojo, es el que le llamamos el Tlahcalli, cuando ya dicen que los aires andan quemando la hierba mala para que nazca la buena, porque ya se acerca el temporal, y hay que limpiar el terreno entonces decían mis abuelos que deberíamos empezar a limpiar el terreno. ${ }^{28}$

Los mitos en la comunidad resaltan que la milpa cobra mayor importancia, ya que está sostenida por procesos identitarios que se encuentran cimentados en actividades básicas y cotidianas, como el hecho de que los campesinos con su trabajo proporcionan seguridad alimentaria y diversas oportunidades de consumo. Lo que implica vivir no simplemente como una cuestión cognitiva, sino como valor o, mejor, como "modelo cultural" susceptible de adhesión colectiva,

${ }^{27}$ Aurelio Ramírez Campos (comunicación personal, 17 de septiembre de 2010).

${ }^{28}$ Aurelio Ramírez (comunicación personal, 27 de octubre de 2011). 
para lo cual se le incorpora a un conjunto determinado de rituales, prácticas y artefactos culturales. ${ }^{29}$ Para Dumézil, ${ }^{30} \mathrm{el} \mathrm{mito} \mathrm{constituye}$ una fuerza; no se trata de una explicación intelectual de una expresión artística, expresa la ideología de la sociedad, al mantener los valores que reconoce y sus ideales, su ser y su estructura misma; justifica las reglas y las prácticas tradicionales.

Planteamientos teóricos factibles para el caso de Amatlán, porque esto se ha conocido de generación en generación, le dan sentido a la existencia de pertenecer a una comunidad, y como consecuencia formar parte de una sociedad con valores y tradiciones. Por esta razon, la mayoría de las familias encuestadas continúan con la siembra de la milpa, porque consideran que es un legado de los dioses y que deben cuidarla y honrarla para garantizar la sobrevivencia; es la actividad económica donde se invierte el trabajo humano y se refuerzan relaciones, gracias a la convivencia de la familia durante las actividades en la producción, pero, sobre todo, es su alimento, su seguridad ante las inclemencias de la vida.

Por esto, los campesinos de Amatlán consideran necesario el continuar cada ciclo agrícola con la siembra de la milpa, y comentan que no se ven a sí mismos viviendo sin sembrar, aunque sea una pequeńa cantidad.

\section{RituALES}

Uno de los aspectos que adquirió mayor relevancia en los nahuas lo constituyó sin duda el ritual. Era el medio por el cual el hombre expresaba de manera tangible su riqueza espiritual y entraba en contacto con el mundo sagrado, con los dioses y con aquello considerado sobrenatural; se buscaba, ganarse la voluntad de las deidades naturales en beneficio de los seres humanos, y a su vez el rito se ofrecía para obtener buenos designios divinos sobre el mundo.

${ }^{29}$ Gilberto Giménez, "Cultura, identidad y memoria. Materiales para una sociología de los procesos culturales en las franjas fronterizas", Frontera Norte 21(41) (enero-junio 2009): 17.

${ }^{30}$ Georges Dumézil, El destino del guerrero, traducción de Juan Almeda (México: Siglo XXI, 1971), 15. 
En Mesoamérica la cosmovisión se fue construyendo durante milenios en torno a la producción agrícola; en esta región se desarrolló una tradición concreta caracterizada por ser producto de sociedades cultivadoras de maíz que vivieron interrelacionadas desde épocas muy tempranas [...] En esta gran área cultural se desarrollaron una serie de ideas, creencias, mitos y rituales que se han mantenido por muchos siglos, principalmente por medio de la tradición oral. ${ }^{31}$

Los elementos tradicionales de la cosmovisión y los cultos a la naturaleza y a la fertilidad agrícola siguen correspondiendo con las condiciones naturales de existencia de las comunidades, lo cual hace comprender su continua vigencia aunque modificada. La lógica campesina actual descansa sobre la base de un sistema de valores, representándolo en diversos, ritos, creencias, fiestas, entre otros; por medio de los cuales agradecen a los montes, a la tierra y a los dioses guardianes del universo, sus bondades para el trabajo y los alimentos que obtienen de ella.

En Amatlán, los rituales agrícolas se realizan en diferentes tiempos del ciclo productivo de la milpa: antes de la siembra, durante el desarrollo de las plantas, en la cosecha o cuando hay escasez de agua. La finalidad es pedir por una buena producción, por una buena época de lluvias, por obtener cosechas abundantes, para agradecer los frutos otorgados por la madre tierra, entre otros; con el propósito de retribuir a los entes divinos de la naturaleza lo que les han dado.

A continuación se mencionan los principales ritos que se llevan a cabo en la comunidad.

\section{Petición de lluvias}

En la actualidad, todavía algunas familias de la comunidad llevan a cabo rituales para pedir agua. Esta solicitud se realizaba desde la época prehispánica, con el fin de mantener a los dioses en armonía y mandaran el agua necesaria para obtener cosechas productivas. Las prácticas ceremoniales se orientan en mantener los equilibrios

${ }^{31}$ Dora Sierra Carrillo, El demonio anda suelto, 23-24. 
necesarios entre el cielo y la tierra; las pertinentes relaciones entre los hombres y los dioses; la nivelación de la balanza del bien y del mal. ${ }^{32}$

No obstante se dice que el ritual de petición de lluvias fue y es muy importante, ya que la base principal de sustento en las comunidades rurales es la agricultura de temporal, por lo tanto, es necesaria el agua para que haya abundantes cosechas, razón por la que algunos pobladores de la comunidad continúan llevando a cabo este rito. De acuerdo con Broda, ${ }^{33}$ quien comenta que "el ritual establece el vínculo entre los conceptos abstractos de la cosmovisión y los actores humanos e implica una activa participación social [...] reside en que éste proyecta la vida colectiva, actuación y cohesión comunitaria e incide en la reproducción de la sociedad y de la identidad grupal".

En Amatlán se tiene la creencia de que la petición de lluvias se realiza cuando el temporal es escaso y cuando a algún agricultor (granicero) se le manifiesta en el sueño una divinidad diciéndole lo que debe hacer para mejorar el periodo de lluvias.

A pesar de que algunas familias continúan con la tradición, cada día son menos las que lo realizan, sin embargo, esto no significa que no lo consideren importante, sino que el trabajo de los habitantes ha ido cambiando y ya no sólo viven de la agricultura, sino de otras actividades como empleados o la formación de negocios propios. Los abuelos ya no tienen la misma fuerza para subir a los cerros, por lo que este evento se lleva a cabo cada vez con menor frecuencia; no obstante, siguen creyendo en el ritual y aún lo ven con respeto porque creen en la energía de la naturaleza.

Este rito se inicia en el cerro más alto de la comunidad que es el Cuauhtzin, donde se realiza una meditación invocando a los cuatro puntos cardinales; se ofrenda copal, la música del tambor y el sonido del caracol y se efectúa un canto que conocen los graniceros (los agricultores que conocen las oraciones y métodos para pedir la lluvia).

${ }^{32}$ Felix Báez-Jorge y Arturo Gómez Martínez, "Los equilibrios del cielo y de la tierra. Cosmovisión de los nahuas de Chicontepec", Desacatos (5) (invierno 2000): 89.

${ }^{33}$ Johanna Broda, "La etnografía de la santa cruz: una perspectiva histórica", en Cosmovisión, ritual e identidad de los pueblos indígenas de México, coord. Johanna Broda y Félix Baéz-Jorge, 175 (México: Fondo de Cultura Económica, 2001), 
Esta ofrenda se brinda primero al oriente, luego al poniente (lugar de la tierra), luego hacia el norte (lugar del aire) y hacia abajo (lugar del agua). Se prenden veladoras en los cuatro puntos cardinales; se da vuelta haciendo un giro de $360^{\circ}$; se conectan las personas con la energía para tener agua durante la producción de la milpa.

A continuación se plasma el comentario de una persona que vive en la comunidad y que es considerado granicero:

Es necesario ir a pedir, eso ayuda a que se ablande el cosmos y ablande el agua. Se pide cuando nos lo piden, por medio de sueños llega el mensaje. El año pasado me llegó un mensaje que tenía que ir al cerro Cuauhtzin, pero atrás del otro lado pegado al cerro, entonces me llegó un mensaje que tenía que estar en el cerro alto por San José de los Laureles que tienen pinturas rupestres, estaba yo sońando que estaba en esa parte pero cuando yo me iba bajando llevaba un estandarte de San Miguel Arcángel, y cuando vi que el agua ya venía encontrándome y así como me llegó el sueño, así sucedió cuando fuimos con Berna (su esposa), Pilar y Pancho (sus hijos). Estábamos haciendo la invocación y pidiendo a los cuatro rumbos el agua, cuando antes de terminar empezamos a sentir el airecito helado helado, y le dije a Berna iya viene el agua, eh!, y vi que ya se había asomado en esta parte de arriba de Tlalnepantla y veía que del Popocatépetl estaba saliendo la otra parte, y le digo hay que apurarnos a terminar porque el agua ya está cerca jeh! Acabamos de bajar, agarramos el coche y cuando bajamos de San José el agua nos encontró, y le dije, ¡mira! el sueño salió real. ${ }^{34}$

El comentario del agricultor antes mencionado coincide con el descubrimiento de la cueva de Chimalacatepec en San Juan Tlacotenco, Tepoztlán, Morelos. ${ }^{35}$

A pesar de que han pasado cientos de años y que este rito se ha ido aprendiendo por la herencia de los abuelos, se puede observar que se mantiene vivo, ya que a partir de la conquista, el culto a los cerros se ha articulado con la religión católica, cuyas fiestas públicas

${ }^{34}$ Norberto Flores Corrales (comunicación personal, 17 de agosto de 2011).

${ }^{35}$ Johanna Broda y Alejandro Robles, "De rocas y aires en la cosmovisión indígena: culto a los cerros y al viento en el municipio de Tepoztlán", en Historia y vida ceremonial, 281. 
giran alrededor de la veneración de los santos, como es el caso del Arcángel San Miguel en la petición de lluvia, ya que la gente de la comunidad cree en la energía de la naturaleza, pero dice que requieren de un santo para que intervenga en la solicitud de un buen temporal.

A mí me gusta ir con mi papá al cerro, veo como hace la ceremonia y estoy empezando a aprender, me gusta hacerlo porque creo en la energía de los cerros para mandar el agua, porque cada año que vamos con mi papá empieza a llover. ${ }^{36}$

Mediante el ritual de petición de lluvias, la comunidad refuerza su identidad y su reproducción cultural. Estas actividades se desarrollan en un marco de comunicación, respeto y transmisión del conocimiento.

Antes yo iba cada año al cerro para hacer la petición de lluvias, nos íbamos varios señores y con todas nuestras familias, ahí rezábamos, incensábamos, prendíamos velas y tocábamos en caracol, después de la ceremonia comíamos y compartíamos nuestros alimentos; pero ahora me duelen las rodillas y ya no puedo caminar bien, imagínate, menos subir, por eso ya no voy, y ahora los jóvenes no tienen tiempo y algunos ya no saben cómo hacerlo, son pocos quienes todavía van, por ejemplo, creo que don Norber todavía va con su familia y los Ramírez. ${ }^{37}$

Se dice que hace cuarenta ańos estos ritos eran algo común entre la gente de la comunidad y que se organizaban para subir a los cerros y realizar esta petición. Para los amatlecos este ritual es importante, porque para ellos las montańas son sagradas y se conciben como deidades atmosféricas, los cerros tienen un papel importante en el ciclo hidrológico, ya que son necesarios en la formación de las nubes cargadoras de la lluvia; ${ }^{38}$ sin embargo, cada vez se llevan a cabo menos, ya que la comunidad con el paso de los años poco a poco ha

${ }^{36}$ Pilar Flores (comunicación personal, 17 de agosto de 2011).

${ }^{37}$ Aureliano Corrales Torres (comunicación personal, 19 de agosto de 2011).

${ }^{38}$ Johanna Broda y Alejandro Robles, "De rocas y aires", 275. 
dejado de ser agrícola, pero persisten las creencias y algunas prácticas culturales, principalmente, de quienes aún siembran con la intención de obtener buenas cosechas; porque la milpa se concibe dentro de una estrategia de sobrevivencia de las familias de las comunidades rurales mediante la cual, junto con otros productos asociados al cultivo y actividades alternas, obtienen la complementación de objetivos de seguridad y de ganancia. Las transformaciones y modificaciones de las estructuras sociales y económicas forman parte de un proceso estructural, temporal y permanente. Las sociedades, tal como se conocen actualmente, son el producto de un proceso constante de transformación social en el cual están involucrados un sinnúmero de factores. Los cambios de Amatlán están relacionados con procesos de modernización comunitaria, familiar o agrícola. Es decir, tanto los espacios familiares como los comunitarios han sido renovados; actualmente la comunidad cuenta con sistemas de comunicación, medios de transporte, centros de salud, escuelas y construcciones más sólidas y modernas; en la agricultura ha implementado fertilizantes e insecticidas químicos, maquinaria agrícola, semillas de variedades mejoradas, entre otros. Por lo que la identidad implica un largo proceso de construcción cultural consciente, en el que intervienen múltiples factores. Sobresalen, entre ellos, compartir el territorio, la historia, las costumbres, los rituales, las tradiciones y creencias. Los recursos esenciales para el funcionamiento de la comunidad son el conjunto de elementos humanos, materiales e institucionales con los que se dispone y a los que se puede recurrir para atender necesidades, resolver problemas y mejorar la calidad de vida.

\section{Rituales agrícolas en Amatlán}

Durante el ciclo agrícola de la milpa, los agricultores realizan diferentes ritos, los cuales son ofrendas en agradecimiento a la fertilidad de la tierra, de las semillas, al beneficio de los aires, de las lluvias, a la productividad de las cosechas, entre otros. Es decir, las acciones de cada plegaria, oración o ritual repercuten directamente sobre las diferentes fases de siembra, crecimiento, cuidado y protección de la agricultura. El campesino no espera que solamente de la contempla- 
ción y oración se arreglen sus problemas agrícolas; él trabaja junto con la oración, en el ambiente y en el cultivo, todo lo cual forma parte del ritual, que para tener éxito debe realizarse paso a paso. ${ }^{39} \mathrm{~A}$ través de los procesos rituales y ceremoniales alrededor de la milpa, establecen convenios para mantener la unión con la naturaleza, con ésta realizan intercambios recíprocos ${ }^{40}$ para solicitar o agradecer los productos obtenidos durante el ciclo agrícola. ${ }^{41}$ De esta manera, pueden afrontar los diversos riesgos y la incertidumbre cotidiana. ${ }^{42}$

El campesino cuida de los cultivos de la milpa por varias razones: porque tiene tierras y no las quieren dejar ociosas, por tradición, por costumbre, por convivencia, por ser un alimento de calidad, pero, sobre todo, porque es una forma de mantener la familia, es su seguridad alimentaria, ya que al tener maíz tienen asegurado su alimento, y lo que sobra; es decir, el excedente es un ahorro, ya que en ocasiones se llegan a presentar situaciones adversas que los orillan a echar mano de su producto para poder contar con dinero en efectivo suficiente para salir del problema; como dicen los entrevistados: para la compra de medicamentos, para la educación de los hijos o para invertir en la siembra del próximo ciclo, entre otros. De esta forma, es evidente que estamos de acuerdo con lo que dice Appendini y De Luca, que parte de la persistencia del grano se debe a que "tener maíz" es un componente de la seguridad alimentaria de los hogares que se funda en una compleja serie de razones, tanto de carácter económico como cultural. Entre las razones de orden cultural podemos citar la costumbre de cultivar para no "perder la parcela" como ejidatario, o el hecho de que para un campesino sembrar el

${ }^{39}$ Tonatiuh Romero Contreras, "Rituales y actividades materiales en la antigua agricultura indígena”, Ciencia Ergo Sum, 11(1) (marzo-junio 2004): 35.

${ }^{40}$ Cessia Esther Chuc Uc, Tsayatsil: El don de la reciprocidad entre los mayas contemporáneos (Campeche: Universidad Autónoma de Campeche, 2008).

${ }^{41}$ Lázaro Hilario Tuz Chi, "Así es nuestro pensamiento. Cosmovisión e identidad en los rituales agrícolas de los mayas peninsulares” (Tesis de doctorado, Universidad de Salamanca, 2009).

${ }^{42}$ Alba González Jácome, "Conversión social y cultural. De los agroecosistemas tradicionales a los alternativos en México", en Los nuevos caminos de la agricultura: procesos de conversión y perspectivas, ed. Alba González Jácome, Silvia del Amo Rodríguez y Francisco Gurri García, 59-95 (México: Universidad Iberoamericana y Plaza Valdés, 2007). 
grano sea un componente de su identidad como persona y miembro de la colectividad rural; además, para convivir con los familiares y amigos mediante los rituales y tradiciones. ${ }^{43}$

Actualmente, en la comunidad de Amatlán, el día 4 de junio se abre la siembra y se cierra el 28 del mismo mes; este periodo es considerado como el más importante; en el que se puede sembrar para obtener una cosecha abundante. Algunas familias acostumbran ponerle incienso a la semilla y rezarle, este rito lo realizan en su casa, posteriormente la llevan a misa, y quienes no van la ponen en el altar doméstico, como se presenta a continuación en los siguientes comentarios:

Se bendice la semilla para sembrar hacen misa y hay que ir a bendecir la semilla no harto poquita el frijol, la calabaza, el maíz y se lleva a la iglesia la bendice el padre ya es como si bendijera toda la semilla que va uno a sembrar y ya lo lleva uno al campo según, pues, para que lo cura del aire le ayude para el aire pa que cuide la milpa. ${ }^{44}$

Nosotros cuando vamos a sembrar sacamos la semillita, la costumbre que me dejo mi mama, que en paz descanse, cuando sacamos la semillita, la ponemos un ratito en el altar en la casa, y ya se está un ratito y después cuando se va a ir al campo y se le pone sahumerio e inciénsamos la semilla, pedimos que esta semilla que se va al campo que regrese, que no se quede allá, que no se pierda, porque ve que luego cuando llueve o no lo laboreamos y no se da, pues, entonces le pedimos a dios que regrese, que nos dé fruto, pues, para que tengamos que comer. ${ }^{45}$

Bueno, pues, lo que hacemos y que aquí nunca se ha perdido, es que cuando se va a sembrar la semilla que vamos a usar, la humea uno, aquí se acostumbra con copal y laurel bendito, se ahúma la semilla para que se limpie, y aquí en el pueblo se acostumbra una misa para bendecir la semilla. ${ }^{46}$

${ }^{43}$ Kirsten Appendini y Marcelo de Luca, Estrategias rurales en el nuevo contexto agrícola mexicano (Roma: faO Naciones Unidas Organización para la Agricultura y la Alimentación, 2006), 28-29.

${ }^{44}$ Socorro Romero Ramírez (comunicación personal, 20 de octubre de 2012).

${ }^{45}$ María Flores Torrescano (comunicación personal, 14 de octubre de 2011).

${ }^{46}$ María Flores Corrales (comunicación personal, 10 de diciembre de 2010). 
También en junio se acostumbra realizar una celebración o fiesta cuando termina la época de labor del cultivo, es decir, según comenta la gente, que una vez que ya se sembró, se abonó y se le dieron las labores necesarias para que la planta crezca, le corresponde a ésta desarrollarse para dar los mejores frutos. Esta ceremonia consiste en brindar una ofrenda a las divinidades de la naturaleza para que haya una buena producción. Se acostumbra que la familia prepare una comida especial: mole verde con pollo, tamales de sal y frijol -elaborados con hojas frescas de la milpa sembrada-.

Estos alimentos se ofrecen junto con agua, tequila, una vela blanca y copal. La ofrenda se basa en estos alimentos porque regresan a la madre tierra lo que ella les dio: el mole verde es por la calabaza, los tamales por el maíz y el frijol. Una vez que se tiene lista se coloca en una piedra grande que se encuentra en medio de la parcela (se dice que la piedra es el centro de energía y que llama a los cuatro puntos cardinales), se prende la vela, se inciensa el lugar y se ofrece a los cuatro puntos cardinales, posteriormente rezan y al término piden a la Madre Tierra y a los dioses que cuiden el cultivo, que el aire no rompa la planta, que las plagas no la dañen, que el granizo no la destruya, que los animales no se la coman, etcétera, y que tengan buena cosecha; al final besan la tierra, como se muestra en la foto 1 .

Los ritos son una expresión religiosa que proporcionan una manera de entrar en contacto con los espíritus de la naturaleza y el maíz para adorarlos, agradecerles, y pedirles más buenos temporales y abundantes cosechas.

El ritual de la acabada es parte importante de nuestras raíces, y nos identifica como indígenas y el amor más que nada a nuestra madre tierra y a la naturaleza, entonces hay que compartir un poquito, ya que nuestra madre tierra nos da todo, o sea nos da alimento y nos cobija, y nosotros hay que dar esa reciprocidad o sea yo te doy tú me das, agradecerle siempre el sustento de lo que nos da de nuestra vida. ${ }^{47}$

Antes cuando terminaban de cultivar en la casa se hacía mole verde de gallina y se llevaba al campo una ollita, y ahí se le ponía según que para los

${ }^{47}$ Leticia Corrales Ramírez (comunicación personal, 19 de mayo de 2010). 
Fото I. Ritual para que haya buena cosecha, Amatlán de Quetzalcóatl

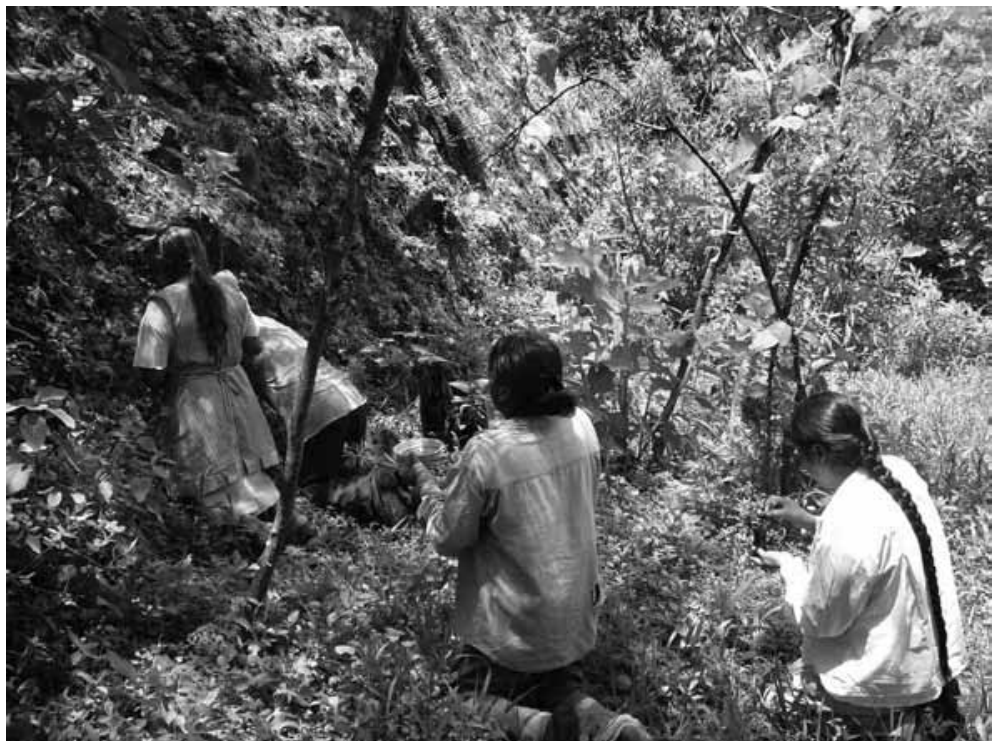

Foto de Erika Román Montes de Oca, agosto de 2010.

aires, para los trabajadores que e iban a trabajar el tiempo, le hacían tamales y se ponían en medio del maíz. ${ }^{48}$

La ceremonia después de que ya se termina de hacer las laboreadas casi ya no la hace la gente, son bien pocas, y quienes la hacen no les gusta que las vean ni que sepa la demás gente, yo creo que por eso ya casi no se hace porque no todos saben hacerla y ya no la enseñan. Nosotros solamente ofrecemos alimentos y prendemos velas y pedimos que nos ayuden los aires, pero no sabemos si así se hace la ceremonia, más o menos tratamos de hacerla. ${ }^{49}$

Otra ceremonia en honor al maíz se realiza en la cosecha: en el primer día de la cosecha-aproximadamente a mediados de diciembre- se llevan los costales cargados de mazorca a las casas para ex-

${ }^{48}$ Tomás Toribio Cazares (comunicación personal, 23 de mayo de 2012).

${ }^{49}$ Ernestina Ramírez Guerrero (comunicación personal, 4 de junio de 2013). 
tenderla y dejarla secar, entonces se reza y se pone incienso, con la intención de agradecer la producción obtenida.

Cuando llega el maicito también lo recibimos con sahumerio, cuando ya cosechamos también recibimos el maíz con sahumerio para darle las gracias de lo que se cosechó. ${ }^{50}$

Yo a veces lo hago todavía, mi papá cuando el primer día que iba a sembrar sea frijol o maíz lo echó en una bolsa el maíz la semilla y empezaba a sahumar con el sahumerio porque según ya se va a salir el maicito pa que rinda, y también cuando cosechamos que vamos a traer el maicito también sahumamos por todos lados la primer carga que descargamos para protegerlo, es lo que hacemos todavía algunos, ya no todos, pero si algunos. ${ }^{51}$

Otro rito de los amatlecos relacionado con la producción de la milpa, se realiza cuando se están asando los elotes de la primera cosecha: la gente adulta toma un elote asado, le da tres vueltas diciendo al mismo tiempo "crece, crece", después le pegan duro en la espalda a un niño y le dan el elote para que se lo coma. Cuando se hace este ritual se cree que los nińos crecen sanos.

Antes cuando éramos niños nos juntábamos y de la milpa agarrábamos elotes y les poníamos lumbre para comer elotes. Dicen que se le pega el elote y se enfría, así es para que crezcan, luego dicen crece crece y le dan tres vueltas, después le pegan duro en la espalda y ya cómetelo. ${ }^{52}$

Este tipo de rituales los llevan a cabo algunas familias, la creencia de algunos pobladores ha disminuido, ocasionando que cada vez se realicen menos porque los jóvenes tienen menor interés y su vida está más influenciada por el capitalismo. Así, pues, estamos de acuerdo con Saldaña: ${ }^{53}$

\footnotetext{
${ }^{50}$ Eucebia Ramírez (comunicación personal, 20 de abril de 2010).

${ }^{51}$ Socorro Romero Ramírez (comunicación personal, 20 de octubre de 2012).

${ }^{52}$ Ignacio Ramírez Torres (comunicación personal, 15 de julio de 2010).

${ }^{53}$ Cristina Saldaña Fernández, Los días de los años, 189-190.
} 
Los rituales públicos o privados se desenvuelven en un marco de comunicación y conocimientos implícitos (visión del mundo) que al sufrir una alteración o desvinculación de su sentido humanitario, pierde su carácter educativo. Pérdida que se da, en muchos casos, al ser objeto de manipulación, por intereses externos al grupo que lo realiza cotidianamente.

A pesar de ello, en la comunidad, la actividad agrícola sigue siendo el principal sustento, ya que gran parte de su vida torna alrededor de la milpa (la preparación del terreno, la siembra, el temporal, cuidado de las plantas, cuidado de las plagas, cosecha, almacenamiento, consumo, venta y las fiestas y rituales que aún se llevan a cabo), porque les da comida a las familias, a los animales y algunas de sus tradiciones están relacionadas con este cultivo, aludiendo a la obtención de alimento. Asimismo, se respetan, ya que los abuelos tienen esa fe, como ellos dicen: todo se va modernizando, según que se va adelantando la humanidad, pero vamos perdiendo valores.

Además, los alimentos elaborados que provienen de la milpa tienen una importancia espiritual en la gente de la comunidad; varios platillos ofrecidos en las ceremonias de agradecimiento a la producción de la milpa son hechos de maíz, calabaza y frijol. Este cultivo forma parte de la cultura y las tradiciones de la comunidad, que coincide con el planteamiento de la UNESCO: ${ }^{54}$

la cocina tradicional se halla transida por un hondo sentimiento religioso, de genuina comunión con el cosmos, que reviste un elaborado tratamiento ritual y ceremonial, y brota de las raíces más profundas, las que se hunden en la población que más cerca está de la tierra, la indígena y la campesina.

Un ejemplo es la creencia de la comunidad sobre la tortilla: la mujer al momento de hacerla, pasa la energía a las personas que la consumirán, es decir, la primera tortilla que las señoras hacen la ponen boca arriba, con la intención de que todos coman sin que nadie

${ }^{54}$ UnesCo, "Pueblo de maíz la cocina ancestral de México", en Cuadernos patrimonio cultural y turismo México, núm. 10 (México: Conaculta, Organización de las Naciones Unidas para la Educación, la Ciencia y la Cultura, 2004), 131. 
se quede sin comer. Además, al hacerla con sus manos pasan su energía a la tortilla, se esponja en el comal y al momento de comerla se transmite la energía a la persona que la consume. Este ritual se refiere a la connotación de la energía, al poder espiritual que se trasmite de una persona a otra.

En coincidencia con Good: ${ }^{55}$

La fuerza $[\ldots]$ se refiere a la energía vital combinada con la fortaleza física y espiritual [...] cuando una persona trabaja transmite su fuerza a otras, y cuando recibe los beneficios del trabajo de otro, uno recibe también su fuerza o energía vital.

Por eso para los nahuas los objetos contienen la fuerza de las personas que los producen [...] ya que cada uno representa el trabajo y contiene la fuerza de diferentes personas; se hacen distinciones entre los objetos de acuerdo a quienes los hicieron con su trabajo.

El ritual puede ser un punto de partida para un acercamiento a la realidad, con la consideración de que ésta se conforma por aspectos materiales e ideales. Dentro del aspecto material se encuentra el espacio físico destinado a la agricultura; la producción de la milpa; la tenencia de la tierra; y las reformas que sobre ésta se han realizado. Lo ideal se expresa a través de las creencias en los aires; de la energía que se trasmite a través de los alimentos; de las ofrendas como agradecimiento que se recrean mediante la tradición oral y dan sentido a las prácticas del ritual agrícola. ${ }^{56}$

\section{MÁs TRAdiciones ViNCULADAS A LA MILPA}

En Amatlán, la tradición y los saberes son substanciales; forman parte de su identidad y persistencia como pueblo náhuatl; se les tienen un enorme respeto; la gente los conoce y recuerda con carińo. Este conocimiento se ha trasmitido de generación en generación, no

${ }^{55}$ Catharine Good Eshelman, "Ejes conceptuales entre los nahuas de Guerrero: expresión de un modelo fenomenológico mesoamericano", Estudios de Cultura Náhuatl (36) (2005): 97.

${ }^{56}$ Saldaña Fernández, Ritual agrícola, 81. 
obstante, cada día menos familias las llevan a cabo, pues, como dice Heller: ${ }^{57}$

Las generaciones adultas constituyen el principal vehículo del saber cotidiano. Sin embargo, es evidente que el saber de la generación sucesiva, incluso en las ciencias orientadas hacia el pasado, no es exclusivamente el saber transmitido. La suma del saber disminuirá o se acrecentará según las necesidades sociales de las respectivas generaciones.

Parte de ello está pasando en la comunidad porque cada día la producción de la milpa va disminuyendo, pero no significa que la han dejado de cultivar, o que han abandonado sus tierras, posiblemente, no producen la misma cantidad y han cambiado algunas estrategias de siembra en comparación con años anteriores; sin embargo, las familias cultivan lo mínimo necesario para cubrir al menos las necesidades anuales de consumo familiar, incluyendo los subproductos útiles para las celebraciones durante el año. Lo que indica que es una comunidad autosuficiente en maíz, porque el campesino no busca con el cultivo una ganancia netamente económica, sino de seguridad alimentaria. La milpa que se cosecha en la comunidad ha formado parte de su vivir diario, ha sido su alimento por siempre, su ahorro, su cultura, su identidad, su cotidianidad, motivo por el cual las familias campesinas continúan con la siembra del grano. Puede haber épocas malas, disminuir su producción, tener trabajos temporales, pero mientras siembren maíz, tendrán seguro su consumo; así dice la gente que este grano es la base de su subsistencia, de su persistencia, de su permanencia, porque no sólo cosechan maíz, sino que obtiene diferentes productos, como el frijol, la calabaza, las hojas de totomoxtle, el rastrojo, entre otros; además, permite convivir con la familia y amigos durante las celebraciones que se llevan a cabo durante su producción.

Por lo tanto, el futuro de la milpa tiene que ver con la permanencia y resistencia de los campesinos; con la historia-identidad del cultivo;

${ }^{57}$ Agnes Heller, Sociología de la vida cotidiana (Barcelona: Ediciones Península, 1977), 320. 
con los programas y políticas gubernamentales; con el compromiso de las familias por mantener sembrando sus tierras como parte de su patrimonio; con el deber de los jóvenes de no perder su identidad y su alimento de calidad. Aun cuando los jóvenes buscan otras oportunidades de vida, son ellos quienes forman parte de los comités o grupos para organizar los rituales o fiestas en relación con la milpa; además, de aportar recursos económicos para la siembra del cultivo, apoyan en la realización de estas ceremonias tanto en lo económico como en lo moral y fisicamente si sus actividades extraagrícolas se lo permiten. Los rituales y fiestas en relación con la milpa constituyen un espacio que reúne fines que comparten valores y símbolos; que fortalecen los lazos de afectividad, de identidad, de reciprocidad; $y$, sobre todo, ayudan a aminorar algunas de las presiones económicas, políticas y sociales al momento de participar en estos eventos, porque como ellos dicen "se olvidan de todo, sólo disfrutan de la organización y de los acontecimientos", ${ }^{58}$ lo que podría ser una forma de relajarse para después conseguir respuestas a las soluciones de las dificultades que tienen o, en su caso, la interacción con las personas para obtener una salida o un consejo.

Ahora, mencionaremos algunas de las tradiciones que se llevan a cabo en la comunidad, y que están relacionadas con el cultivo del maíz.

\section{Semana Santa}

Las tradiciones que aún se realizan por la mayoría de las familias acontecen antes de la Cuaresma. Inician en el mes de marzo: veinte días antes del Viernes Santo empiezan los preparativos para la época de la Semana Santa, este día se tiene por costumbre que se siembra maíz en maceteros (veinte días antes del Viernes Santo, por lo regular, en el mes de marzo) con la intención de que para el día Viernes de Semana Santa, la planta tenga una altura de $30 \mathrm{~cm}$. El maíz que se pone a germinar es de todos los colores existentes: azul, rojo, amarillo y blanco. Cuando llega la Semana Santa las macetas son llevadas a la parroquia,

${ }^{58}$ Ernestina Ramírez Guerrero (comunicación personal, 20 de agosto de 2011). 
se colocan en el altar como ofrenda a los santos para que proporcionen tranquilidad y paz en la resurrección de Cristo.

En Semana Santa se siembran las semillas de maíz en maceteros para llevar las plantas al altar y eso representa adornar al santo para tener tranquilidad y paz, también está la tradición del 15 de mayo de san Isidro Labrador es cuando se lleva a bendecir la semilla de maíz y calabaza que es la que se va a sembrar. ${ }^{59}$

Cuando va a hacer el Viernes Santo, que es cuando nuestro señor Jesús lo martirizan le hacen muchas cosas lo crucifican y entonces es como ofrenda, pero eso lo ponemos en macetitas el maíz, y la milpita debe estar como $20 \mathrm{~cm}$. Se pone en el altar, y la semilla se siembra 20 días antes del viernes santo para que estén grandecitas. ${ }^{60}$

\section{SAN IsIDRo LABRADOR}

El 15 de mayo es un día muy importante para la comunidad ya que se comienzan a preparar los campos de cultivo, los utensilios de labranza y las yuntas. Es un día de fiesta, es el día del santo patrono de los agricultores: san Isidro Labrador. Anteriormente se adornaba a los animales con ramas y flores del campo, pero ahora sólo se realiza una misa y, posteriormente, se bendicen las semillas que se sembrarán en el ciclo agrícola.

Cuando aquí hay misa se lleva el maíz a la iglesia en san Isidro el 15 de mayo, se lleva el maíz, el frijol o lo que se va a poner en el campo y se escucha la misa y ya se lleva al campo. Cuando vamos a misa consigo agua bendita, y yo le doy a mi esposo que lo eche alrededor para que no lo tire el aire o cuando se lo llevan antes de que se lleven la semilla, veía que mi mamá así le hacía, y entonces pongo sahumerio le echo copal y lo paso al maíz con un ayate, le echo copal y le paso el sahumerio y ya se lleva ya está bendito. ${ }^{61}$

${ }^{59}$ Laura Ramírez Torrescano (comunicación personal, 22 de mayo de 2010).

${ }^{60}$ María Flores Torrescano (comunicación personal, 14 de octubre de 2011).

${ }^{61}$ Nicolasa Flores Corrales (comunicación personal, 2 de septiembre de 2011). 
El 15 de mayo se llevaba a bendecir todo, antes todos trabajaban con yunta de bueyes y todos los bueyes los adornaban, los llevaban a la iglesia y ahí los bendecía el padre, hacían comida y todos tenían la creencia, por ejemplo, de que el buey era bendito por Dios cuando nació con su resuello le dio calor en el pesebre y por eso Dios lo bendijo y cuando pasa el buey dentro la milpa y va resollando el maíz crece bonito, le va dando la energía, el aliento. ${ }^{62}$

\section{Fiesta del Pericón (Tagetes Lucida Cav.) ${ }^{63}$}

En el mes de septiembre es la Fiesta del Pericón (yuaubtli), el día 28 es cuando se pueden comer los primeros elotes de la cosecha que la tierra ofrece.

Según la tradición de la cultura náhuatl, es el día de la diosa Xilonen, también conocida como diosa del maíz tierno o del elote tierno, "la explicación filosófica de esta fiesta es que nuestra manutención contiene el espíritu de Xilonen que muere entre nuestros dientes para darnos vida". ${ }^{64}$ A mediados de este mes termina el periodo de lluvias fuertes y el día 28 se realizan rituales con varios elementos simbólicos, siendo el principal la flor de pericón, por lo que mucha gente llama a esta fiesta la del pericón. Dicho festejo consiste en ir a cortar la planta para posteriormente elaborar las cruces, éstas son colocadas en los cuatro puntos cardinales de los cultivos de la milpa, además se colocan en las entradas de la parcela, como se muestra en la foto 2, en las casas, en las puertas, en las ventanas, en los carros, en los comercios, etcétera. Estas cruces se colocan con la intención de protegerse, según la creencia, de los aires o del demonio. Se dice que en la noche se sueltan los aires o el demonio para dañar los cultivos, a las personas o los bienes materiales.

${ }^{62}$ Tomás Toribio Cazares (comunicación personal, 23 de mayo de 2012).

${ }^{63}$ Es una planta silvestre que crece en la comunidad: "a su llegada los espańoles le llamaron pericón, pero su nombre en lengua nativa es yiauhtli [...] tiene un tallo purpúreo, se divide como a unos veinte centímetros de la corona en cero, tres y hasta seis tallos, que se vuelven a dividir en tres más que cargan la flor. Ésta se compone de dos pétalos [...] Las hojas tienen forma de lanza y se encuentran en pares en el tallo, finalmente aserradas con poco aumento de tamaño hacia abajo". Carmen Cook, "El yauhtli; o pericón", 41."

${ }^{64}$ Carmen Cook, "El yauhtli o pericón", 49. 
Fото 2. Milpa protegida con flores de pericón

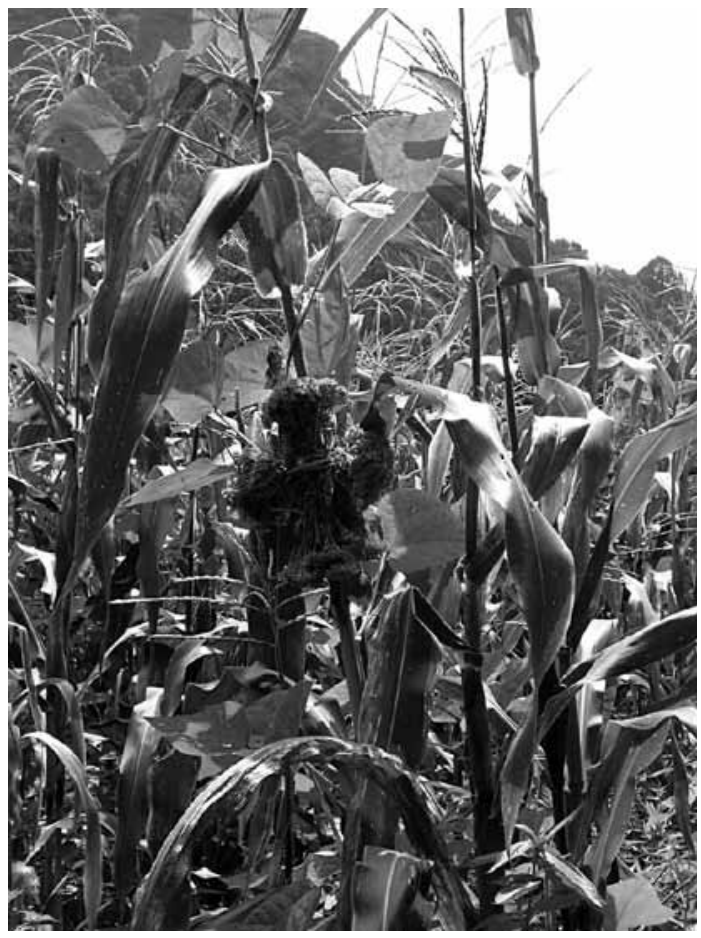

Foto de Erika Román Montes de Oca, agosto de 2010.

Desde que crecí, año con año, yo veía a mis abuelitos que iban a cortar las flores y llevaban sus ayatitos y en cada esquina ponían las cruces y luego nos decían para que retire el aire para que no pase por ahí [hijo] y aparte de las milpas también las casas, tendrá algún significado pero yo no me doy cuenta. Esas cruces son para protegernos del mal o de los aires. ${ }^{65}$

El 28 se van a dejar en el campo en cada esquina [cruces con flores de pericón], se pone una y luego también en medio donde está sembrado en las milpitas se deja una cruz, significa, pues, dicen que para que no entre el

${ }^{65}$ Lázaro Ramírez Cázares (comunicación personal, 27 de octubre de 2011). 
hambre, porque San Miguelito entra para que no entre el mal, ya ve que luego el aire lo tira, hace aire y lo llega a tirar. ${ }^{66}$

Esa tradición ya tiene mucho desde que era niño me acuerdo que mi papá me llevaba a caballo allá a la milpa, llegamos allá arrancar escobas el mero 28 , a comer elotes, es una tradición que todas las familias salen a comer elotes un día como de fiesta que sale uno a comer al campo [...] Pues, los antepasados son los que nos dejaron esta tradición que seguimos para el mal que no pase por la milpa para tumbar el aire que no pase por la milpa, por ejemplo, la aerión que según el chamuco, pues, ya con la cruz de flor ya se lo pones para que se le retire. ${ }^{67}$

Esta tradición en la comunidad de Amatlán de Quetzalcóatl está más relacionada con los aires y es muy importante el colocar las cruces de pericón, de lo contrario, los aires entrarán en cualquier lugar y provocarán daño. Algunas familias comentan que en años pasados la gente acostumbraba comer elotes para estar pesados y, así, cuando llegaran los aires no se los llevaran. En el campo asaban los elotes y comían lo más que podían: a eso le llaman la tlaxquiada.

Este mismo día, muchas familias se reúnen en los campos de cultivo para festejar la famosa elotada: los dueños de la parcela invitan a los amigos y familiares de diferentes lugares de la comunidad para compartir los elotes asados. Después de un caluroso saludo, el jefe de familia y los hijos en compañía de los invitados van a cortar los elotes más tiernos. La indicación que dan a los visitantes sobre cuales elotes se deben cortar es que al apretarlos fuertemente no se deben aplastar los granos, posteriormente se le quita la hoja y se ponen a las brasas con la leña. Las mujeres de algunas familias cocinan chileatole, una preparación hecha con chile guajillo, epazote, sal y los granos de elote; es un atole muy sabroso. La gente comparte los alimentos mientras se disfruta de una charla muy amigable.

Para los pobladores de Amatlán, el demonio representa el sufrimiento del hambre, que se hace patente en septiembre; por eso san Miguel lo enfrenta y,

${ }^{66}$ Nicolasa Flores Corrales (comunicación personal, 2 de septiembre de 2011).

${ }^{67}$ Socorro Romero Ramírez (comunicación personal, octubre 20, 2012). 
al vencerlo, acaba con la carencia de alimentos. El día 28 se cosechan los primeros elotes y se colocan las cruces de pericón en los sembradíos, para evitar que el chamuco, en la forma de aires malignos, ocasione dańos y destruya los cultivos. ${ }^{68}$

\section{Conclusión}

El presente estudio ha tenido como eje de análisis la importancia cultural de la producción de la milpa en la comunidad de Amatlán de Quetzalcóatl, municipio de Tepoztlán, en el contexto actual de las transformaciones del estado de Morelos y de México. A lo largo de este trabajo, se han abordado las relaciones que al interior de la cultura campesina se establecen entre la producción y los rituales agrícolas del cultivo de la milpa; así como con la cosmovisión y el culto a la naturaleza. Esta analogía que existe entre la milpa y el humano, en la que se necesitan una del otro, se ha dado desde su creación para la sobrevivencia del campesino; ha formado parte de las creencias, conocimientos, ritos, mitos y prácticas religiosas. Obviamente han cambiado, pues, la comunidad con el paso del tiempo, poco a poco ha disminuido la producción de la milpa, pero persisten las creencias y algunos rituales.

La relación de la milpa con la tradición, como se evidenció en esta investigación, tiene que ver con una visión del mundo enlazada con las manifestaciones meteorológicas y astrales que son útiles para el pronóstico del temporal y la fecha de obtención de la producción. Como lo menciona Hernández, los campesinos han aprendido a diagnosticar la llegada de los temporales; a conocer la mejor época de siembra o cosecha; a ir adaptando la semilla de acuerdo con las condiciones ecológicas de la comunidad; $y$ a cuidar de la milpa durante todo el ciclo productivo. ${ }^{69}$

De esta manera, se enfatiza que la milpa cobra mayor importancia en la comunidad en tanto está sostenida por procesos identitarios que destacan la permanencia de saberes y rituales agrícolas a través del tiempo, porque son prácticas culturales que sostienen su

${ }^{68}$ Dora Sierra Carrillo, El demonio anda suelto, 135.

${ }^{69}$ Marcela Hernández Ferrer, "Idhidh kwitol: niño maíz. Los niños en los rituales agrícolas de los Teenek de la Huasteca Potosina” en Historia y vida ceremonial, 231. 
alimentación y la economía familiar. En la presente investigación se argumentó y de estos argumentos se desprende la idea de que la milpa es tradición porque desde la época prehispánica el maíz representó la razón de ser, el corazón o fundamento de las cosas, hecho que el pueblo de Amatlán actualmente reconoce, donde su vida cotidiana está relacionada con este cultivo, y las ofrendas se hacen con la finalidad de poder obtener abundantes cosechas.

También se observó que a pesar de que la comunidad ha sido muy respetuosa con sus mitos, creencias, ritos y tradiciones; los han realizado cada día menos, y esto es porque los jóvenes tienen poco interés en la producción de la milpa y, además, su vida está más influenciada por las actividades extraagrícolas. Sin embargo, los mitos, ritos, tradiciones y fiestas que se siguen llevando a cabo son parte de su identidad y del apego efectivo que la gente le tiene al cultivo; la razón principal es que forma parte de su alimentación y sustento. Además, se debe a que han mantenido su estrategia de reproducción de modo múltiple, la cual incluye la milpa y otras actividades productivas como servicios de medicina tradicional, puestos de tortillas, empleados en hoteles, empleados domésticos, entre otros.

Algunas de estas celebraciones que la mayoría de las familias amatlecas llevan a cabo son la de San Isidro Labrador, que es la preparación de la semilla para la siembra; la Fiesta del Pericón que se relaciona con la elotada; y la de agradecimiento por la cosecha recibida.

Los ritos tienen una creencia relacionada con las fuerzas místicas, la comunidad se reajusta a las condiciones cambiantes y a los valores de ésta como parte de su identidad.

\section{ENTREVISTAS PERSONALES}

Leticia Corrales Ramírez (comunicación personal, 19 de mayo de 2010).

Aureliano Corrales Torres (comunicación personal, 19 de agosto de 2011).

Pilar Flores (comunicación personal, 17 de agosto de 2011).

María Flores Corrales (comunicación personal, 10 de diciembre de 2010). 
Nicolasa Flores Corrales (comunicación personal, 2 de septiembre de 2011).

Norberto Flores Corrales (comunicación personal, 17 de agosto de 2011).

María Flores Torrescano (comunicación personal, 14 de octubre de 2011).

María Asunción Guerrero Robles (comunicación personal, 13 de febrero de 2012).

Aurelio Ramírez (comunicación personal, 27 de octubre de 2011).

Eucebia Ramírez (comunicación personal, 20 de abril de 2010).

Lázaro Ramírez Cázares (comunicación personal, 27 de octubre de 2011).

Aurelio Ramírez Campos (comunicación personal, 17 de septiembre de 2010).

Ernestina Ramírez Guerrero (comunicación personal, 20 de agosto de 2011 y 4 de junio de 2013).

Ignacio Ramírez Torres (comunicación personal, 15 de julio de 2010). Laura Ramírez Torrescano (comunicación personal, 22 de mayo de 2010).

Socorro Romero Ramírez (comunicación personal, 20 de octubre de 2012).

Tomás Toribio Cazares (comunicación personal, 23 de mayo de 2012).

\section{REFERENCIAS BIBLIOGRÁFICAS}

Alvarado Peralta, Felipe. Fundación de Amatlán. Cuernavaca: Anzaldo Meneses, 1988.

Appendini, Kirsten y Marcelo DE LUCA, Estrategias rurales en el nuevo contexto agrícola mexicano. Roma: $\mathrm{FAO}$, ONU, Organización para la Agricultura y la Alimentación, 2006.

BrodA, Johanna. "La etnografía de la santa cruz: una perspectiva histórica". En Cosmovisión, ritual e identidad de los pueblos indigenas de México, coord. Johanna Broda y Félix, Baéz-Jorge, 165238. México: Fondo de Cultura Económica, 2001.

BrodA, Johanna y Alejandro Robles. "De rocas y aires en la cosmovisión indígena: culto a los cerros y al viento en el municipio de 
Tepoztlán”. En Historia y vida ceremonial en las comunidades mesoamericanas: los ritos agrícolas. Colección Etnografía de los Pueblos Indígenas de México. Serie Estudios Monográficos, coord. Johanna Broda y Catharine Good Eshelman, 271-288. México: Conaculta, INAH, UNAM/IIH, 2004.

Cook, Carmen. "El yauhtli o pericón. Flor mágica de los antiguos mexicanos". En La historia de Amatlán de Quetzalcóatl, comp. Felipe Alvarado Peralta, 39-47. Cuernavaca: Anzaldo Meneses, 1987. Corona Caraveo, Yolanda y Carlos Pérez Zavala. "Resistencia e identidad como estrategias para la reproducción cultural". Anuario de Investigación, vol. II (2002): 57.

Chuc Uc, Cessia Esther. Tsayatsil: El don de la reciprocidad entre los mayas contemporáneos. Campeche: Universidad Autónoma de Campeche, 2008.

DumÉzIL, Georges. El destino del guerrero. Traducción de Juan Almeda. México: Siglo XXI, 1971.

Báez-Jorge, Felix y Arturo Gómez Martínez. "Los equilibrios del cielo y de la tierra. Cosmovisión de los nahuas de Chicontepec", Desacatos (5) (invierno 2000): 79-94.

GIMÉNEZ, Gilberto. "Identidades étnicas: estado de la cuestión". En Los restos de la etnicidad en los Estados nación del siglo XXI, coord. Leticia Reina, 45-70. México: Ciesas, INI, Porrúa, 2000.

. "Cultura, identidad y memoria. Materiales para una sociología de los procesos culturales en las franjas fronterizas", Frontera Norte 21(41) (enero-junio 2009): 7-32.

Gómez Espinoza, José Antonio. Maiz, axis mundi. Maiz y sustentabilidad. México: Juan Pablo Escobar, 2011.

González Jácome, Alba. "Conversión social y cultural. De los agroecosistemas tradicionales a los alternativos en México". En Los nuevos caminos de la agricultura: procesos de conversión y perspectivas, ed. Alba González-Jácome, Silvia del Amo Rodríguez y Francisco Gurri García, 59-95. México: Universidad Iberoamericana, Plaza y Valdés, 2007.

GonZÁLez, ToRres, Yolotl. "Notas sobre el maíz entre los indígenas mesoamericanos antiguos y modernos. Dimensión Antropológi$c a$, año 14, vol. 41 (septiembre-diciembre 2007): 45-80. 
Good Eshelman, Catharine. "La vida ceremonial en la construcción de la cultura: proceso de identidad entre los nahuas de Guerrero". En Historia y vida ceremonial en las comunidades mesoamericanas: Los ritos agrícolas, Colección Etnografía de los Pueblos Indígenas de México. Serie Estudios Monográficos, coord. Johanna Broda y Catharine Good Eshelman, 127. México: Conaculta, INAH, UNAM/IIH, 2004.

. "Ejes conceptuales entre los nahuas de Guerrero: expresión de un modelo fenomenológico mesoamericano". Estudios de Cultura Nábuatl (36) (2005): 87-113.

Guerrero Arias, Patricia. La cultura estrategias conceptuales para entender la identidad, la diversidad, la alteridad y la diferencia. Quito: Abya-Yala, 2002.

Gutiérez Serrano, Norma Georgina. "Relatos de vida productiva alrededor del maíz. Cultura, conocimiento y aprendizaje", Revista de Cultura, Identidad y Educación, año 4(7) (2009): 92.

. "Cultura, conocimiento y aprendizaje". En Relatos, conocimientos y aprendizaje en torno al cultivo del maiz en Tepoztlán, coord. Norma Georgina Gutiérrez Serrano, 41-64. México: Juan Pablos, CRIM, 2010.

Gutiérez Serrano, Norma Georgina y José Antonio Gómez EsPINOSA. "Relatos de vida productiva alrededor del maíz. Maíz, milpa, conocimiento y saberes locales en comunidades agrícolas". En Saberes colectivos y diálogos de saberes en México, coord. Arturo Argueta Villamar, Eduardo Corona-M. y Paul Hersh Martínez, 329-344. México: UnAM, 2011.

Heller, Agnes. Sociología de la vida cotidiana. Barcelona: Editorial Península, 1977.

HernÁNDEZ FerRer, Marcela. "Idhidh kwitol: niño maíz. Los niños en los rituales agrícolas de los Teenek de la Huasteca Potosina". En Historia y vida ceremonial en las comunidades mesoamericanas: los ritos agrícolas. Colección Etnografía de los Pueblos Indígenas de México. Serie Estudios Monográficos, coord. Johanna Broda y Catharine Good Eshelman, 215-233. México: Conaculta, INAH, UNAM/IIH, 2004. 
INAI. Fiestas y rituales en la conservación de la agrobiodiversidad en el Perú. Lima: Instituto Nacional de Investigación Agraria, 2007. Lupo, Alessandro. "La cosmovisión de los nahuas de la Sierra de Puebla". En Cosmovisión, ritual e identidad de los pueblos indígenas de México, coord. Johanna Broda y Felix Báez-Jorge, 335389. México: Fondo de Cultura Económica, 2001.

López Austin, Alfredo. Cuerpo humano e ideología las concepciones de los antiguos nahuas I. México: UnAM, 1980.

Romero Contreras, Tonatiuh. "Rituales y actividades materiales en la antigua agricultura indígena”, Ciencia Ergo Sum 11(1) (marzo-junio 2004): 25-35.

SAldaña Fernández, Cristina. Ritual agrícola en el suroeste de Morelos: la fiesta de la ascensión. México: Plaza y Valdés, 2010.

. Los días de los años: ciclo ritual en el suroeste de Morelos. México: Juan Pablos, 2011.

SIAP-SAGARPA. Situación actual y perspectivas del maiz en México 1996-2012. México: Servicio de Información Agroalimentaria y Pesquera, Secretaría de Agricultura Ganadería Desarrollo Rural Pesca y Alimentación, 2007, http://www.campomexico.gob.mx (Fecha de consulta: 31 de enero de 2015).

Sierra Carrillo, Dora. El demonio anda suelto. El poder de la cruz de pericón. México: INAH, 2008.

Terán, Silvia y Christian Rasmussen. "La milpa bajo roza-tumbaquema en el siglo Xvi”. En La modernización de la milpa en Yucatán: utopia o realidad, ed. Daniel Zizumbo Villarreal, Christian Rasmussen, Luis Arias Reyes y Silvia Terán Contreras, 29-51. Mérida: Centro de Investigación Científica de Yucatán, DanidaDinamarca. 1992.

Tuz Chi, Lázaro Hilario. "Así es nuestro pensamiento. Cosmovisión e identidad en los rituales agrícolas de los mayas peninsulares". Tesis de Doctorado, Universidad de Salamanca, 2009.

unesCo. "Pueblo de maíz la cocina ancestral de México". En Cuadernos patrimonio cultural y turismo México. Núm. 10. México: Conaculta, Organización de las Naciones Unidas para la Educación, la Ciencia y la Cultura, 2004, 131. 